\title{
Household Essential Oils as Antimicrobial Agents for Health and Skin care
}

\section{HAYA ADEL ALFASSAM ${ }^{1 *}$,FADILAH SFOUQ ALEANIZY², FULWAH YAHYA ALQAHTANI², ALANOUD MOHAMMED ALTALAL ${ }^{2}$ and RAWAN ANWAR FITAIHI ${ }^{2}$}

\author{
${ }^{1}$ King Abdulaziz City for Science and Technology, Riyadh, Saudi Arabia. \\ 2Department of Pharmaceutics, College of Pharmacy, King Saud University, \\ Riyadh, Saudi Arabia. \\ ${ }^{*}$ Corresponding author E-mail: halfassam@kacst.edu.sa \\ http://dx.doi.org/10.13005/ojc/330464
}

(Received: April 19, 2017; Accepted: July 04, 2017)

\begin{abstract}
Essential oils have been traded and consumed in every house, for either health and skin care purposes. Essential Oils are volatile, concentrated, hydrophobic liquids containing aromatic compounds from plants. They are obtained via steam or hydro-distillation, it has been used as food remedies or beauty product and can be easily obtained from the local markets. The aim of this study is to investigate the antimicrobial effect of the most used commercial essential oils (Black seed, Lemongrass, Oregano, Marjoram) against selected microorganisms. Antimicrobial activity of the selected essential oils was investigated using agar diffusion method. Candida albicans (ATCC 10231) as fungus, Escherichia coli (ATCC 25922), Staphylococcus epidermidis (ATCC 14990) Pseudomonas aeruginosa (ATCC 27853) were used in this study and adjusted according to the Clinical and Laboratory Standards Institute (CLSI). The results showed that the Black seed oil has the most potential bactericidal effect.
\end{abstract}

Keywords: Essential oil, Black seed oil, Lemongrass oil, Oregano oil, Marjoram oil, home remedies, antimicrobial effect.

\section{INTRODUCTION}

Essential oils also called volatile oils are aromatic liquids retrieved from plant materials flowers, buds, seeds, leaves, twigs, bark, herbs, wood, fruits and roots. They can be obtained by different methods such as fermentation, expression or extraction and the most commonly commercial production method used is the steam distillation. Plant essential oils and extracts have been used for many millenniums ${ }^{1}$, in the alternative medicine, food preservation and natural therapies. Essential oils have been traditionally used for pharmaceutical purposes as antibacterial and antifungal agents in different areas of the world ${ }^{2}$. The chemical profile of each essential oil is different not just chemically but 
structurally as well, hence why they are extracted according to their purpose of use, e.g for perfume uses, extraction by carbon dioxide and lipophilic solvents are used rather than steam distillation. So that in order to obtain the quality and quantity of the oils they have to be extracted at the same conditions to reach the constant composition, from the same organ of the same plant, from the same soil, picked in the same season and under the same climate ${ }^{3,4}$.

3000 estimated essential oils are known, of that 300 have commercially importance in fragrance and beauty markets ${ }^{3}$. Essential oils are lipid soluble and this feature helps them to pass through the cell membranes and leads to leakage of "macromolecules", leading to cell lysis ${ }^{5}$. In the case of bacteria, this is associated with the damaging of the ion channel proton pumps, leading to a reduction in membrane potential. Damage to the proton pump will lead to a reduction of ATP being produced by the cell6.

All previous studies focused on testing the in-vitro antimicrobial activity of pure essential oils such as; black seed, lemongrass, marjoram and oregano oils, but there are no studies revealed regarding the activity of the same oils intended for commercial use for hair and skin.

\section{Aim of the study}

This study was conducted to investigate the antimicrobial activity of selected essential oils treated for commercial use for health and skin care, against different microorganisms.

\section{MATERIAL AND METHODS}

Essential oils were purchased from the local Saudi market, Tween 20 (Sigma), normal saline, Mueller Hinton medium (Oxoid), and sterilized discs (Whatman no. 5, $6 \mathrm{~mm}$ diameter) were purchased.

\section{Preparation of the essential oils samples}

The oils were purchased from local markets and dissolved in normal saline with tween 20 then impregnated in sterilized discs with different concentrations $(1: 1,1: 5,1: 10,1: 20)$ each disc had $25 \mu \mathrm{L}$.

\section{Microbial preparation}

Candida albicans (ATCC 10231), Escherichia coli (ATCC 25922), Staphylococcus epidermidis (ATCC 14990) Pseudomonas aeruginosa (ATCC 27853) were used in this study. The bacteria suspension was prepared and adjusted by comparison against $0.5 \mathrm{McF}$ arlan turbidity standard $\left(5 \times 10^{7}\right.$ organisms $\left./ \mathrm{ml}\right)$ in accordance with the Clinical and Laboratory Standards Institute (CLSI) ${ }^{7}$.

\section{Measuring the antimicrobial activity by disc diffusion method}

Mueller Hinton culture medium was distributed in Petri plates $(100 \times 20 \mathrm{~mm})$ forming a base layer of $10 \mathrm{ml}$. After solidification of the medium, $10 \mathrm{ml}$ of medium containing microbial inoculums $1 \%$ in the range of approximately $10^{5}$ $\mathrm{CFU} / \mathrm{ml}$ were distributed over the base layer to form the seed layer. The selected essential oils were dissolved in normal saline with Tween $20(0.5 \% \mathrm{v} / \mathrm{v})$.

Table1: Antimicrobial activity of the selected essential oils against selected strains by disc diffusion method

\begin{tabular}{lllll}
\hline & \multicolumn{4}{c}{ Essential oils } \\
\cline { 2 - 5 } Microorganism & Marjoram oil & Oregano oil & Lemon grass oil & Black seed oil \\
\hline \multirow{2}{*}{ Staphylococcus epidermidis } & $20 \pm 0.3$ & $\mathrm{NI}$ & $19 \pm 0.1$ & $28 \pm 0.2$ \\
Escherichia coli & $30 \pm 0.3$ & $30 \pm 0.2$ & $20 \pm 0.2$ & $30 \pm 0.4$ \\
Pseudomonas aeruginosa & $\mathrm{NI}$ & $30 \pm 0.1$ & $\mathrm{NI}$ & $30 \pm 0.2$ \\
Candida albicans & $\mathrm{NI}$ & $\mathrm{NI}$ & $\mathrm{NI}$ & $\mathrm{NI}$ \\
\hline
\end{tabular}

Gentamycin $(25 \mu \mathrm{g})$ was used as a positive reference standard; Values are mean inhibition zone $(\mathrm{mm}) \pm$ S.D of the triplicate. Means are statistically significant by ANOVA test at $\mathrm{p}=0.05 ; \mathrm{NI}=$ no activity 
Sterilized discs (Whatman no. 5, $6 \mathrm{~mm}$ diameter) were infused with $(25 \mu \mathrm{L})$ of different concentrations $(1: 1,1: 5,1: 10,1: 20)$ of the relevant essential oils and placed on the agar surface. Gentamicin disc $(25 \mu \mathrm{g})$ was used as control. The plates were incubated at $37^{\circ} \mathrm{C}$ for 24 hours and the reading of the diameters of inhibition zones $(\mathrm{mm})$ was performed. The studies were conducted in triplicate. The results were expressed as mean $\pm S D$. $P$ values $<0.05$ were considered as significant using ANOVA test $(1,4)$.

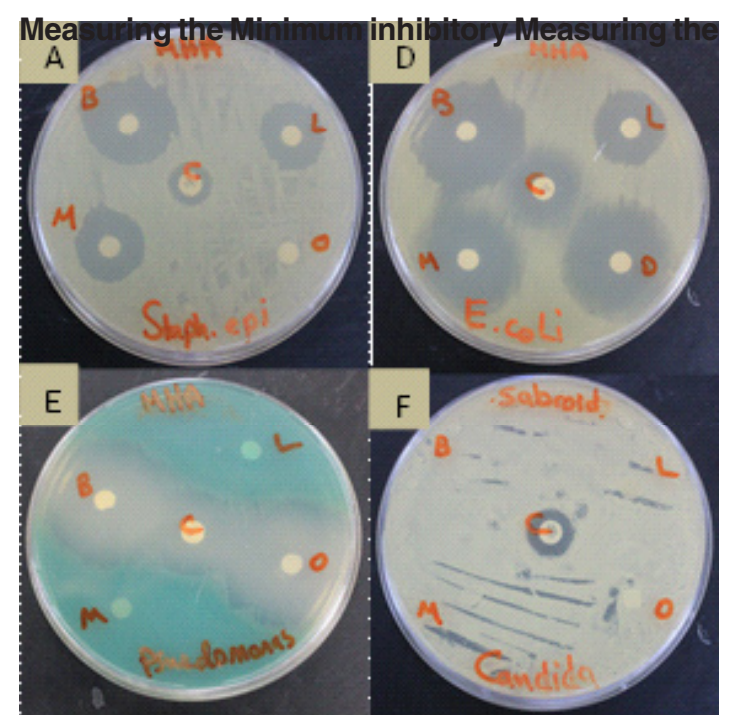

Fig.1: Antimicrobial activity of essential oils (B) black seed, (L) lemongrass, (O) oregano and (M) marjoram against bacteria and yeast, (A) Staphylococcus epidermidis, (D) Escherichia coli, (E) Pseudomonas aeruginosa, (F)

Candida albicans, using disc diffusion. Control antimicrobial agents (C) Gentamycin with the concentration of $(25 \mu \mathrm{g})$

\section{Minimum inhibitory concentration}

A series of two fold dilution of each oil was prepared, ranging from 10 to $50 \mathrm{mg} / \mathrm{ml}$. A final concentration of $(0.5 \% \mathrm{v} / \mathrm{v})$ Tween-20 (Sigma) was incorporated to enhance oil solubility. Aliquots of culture containing relatively $10^{5} \mathrm{CFU} / \mathrm{ml}$ of each organism were incubated at $37{ }^{\circ} \mathrm{C}$ for 24 hour. Experiments were carried out in triplicate. Inhibition of bacterial growth in the test tubes containing tested oils was evaluated by comparison with growth in blank control tubes. The minimum inhibitory concentration were determined as the lowest concentration of oil inhibiting the visible growth of each tested organism ${ }^{1,2,4,7}$.

\section{RESULTS AND DISCUSSION}

The antibacterial activity of the four selected oils against the selected species is summarized in table 1 and 2, also shown in figure 1. The results revealed that the selected essential oils showed antibacterial activity with varying magnitudes but there was no antifungal activity shown. The zone of inhibition for total diameter smaller than $(8 \mathrm{~mm})$ was taken as non-sensitive (NI); for total diameter between (9-14mm) considered as sensitive; for total diameter between (15-19 $\mathrm{mm}$ ) was taken as very sensitive and for total diameter larger than (20mm) extremely sensitive. All selected oils showed activity against Escherichia coli and all oils except oregano showed activity against Staphylococcus epidermidis. Black seed and oregano oils revealed strong activity against Pseudomonas aeruginosa. Minimum inhibitory concentration of all tested oils was four to five-folds less as compared to the pure oils documented in literatures.

Table 2: Minimum inhibitory concentration (MIC) of the selected essential oils (mg/ml) against selected strains by two-fold dilution method

\begin{tabular}{lllll}
\hline & \multicolumn{4}{c}{ Essential oils } \\
\cline { 2 - 4 } Microorganism & Marjoram oil & Oregano oil & Lemongrass oil & Black seed oil \\
& & & \\
\hline & & $\mathrm{NI}$ & $\geq 0.4$ & \\
Staphylococcus epidermidis & $\geq 2$ & $\geq 0.8$ & $\geq 0.7$ & $\geq 26$ \\
Escherichia coli & $\geq 0.8$ & $\geq 11$ & $\mathrm{NI}$ & $\geq 31$ \\
Pseudomonas aeruginosa & $\geq 12$ & $\mathrm{NI}$ & $\mathrm{NI}$ & $\mathrm{NI}$ \\
Candida albicans & $\mathrm{NI}$ & & \\
\hline
\end{tabular}

Values of MIC are mean of three replicates, $\mathrm{NI}=$ no activity. 


\section{CONCLUSION}

From this study it can be concluded that many commercially available essential oils possess antibacterial activity. Black seed oil has the most potential bactericidal properties against Grampositive Staphylococcus epidermidis and Gram negative bacteria Escherichia coli and in particular pathogenic Pseudomonas aeruginosa, however, no antifungal activity was demonstrated. We believe that the present investigation combined with previous studies provide support to the antibacterial properties of commercially accessible oils specially those for hair and skin care and for food as well.

\section{ACKNOWLEDGMENT}

We express our gratitude to the Joint Center of Excellence Program at King Abdul Aziz City for Science and Technology, Riyadh, Saudi Arabia.

\section{REFERENCES}

1. Burt, S.A, Essential oils: their antibacterial properties and potential applications in foods: a review. International journal of food microbiology. 2004, 94 , 223-253.

2. Prabuseenivasan, S.; Jayakumar, M.; Ignacimuthu, S, In vitro antibacterial activity of some plant essential oils. BMC complementary and alternative medicine. 2006, 6(1) , 39

3. Bakkali, F.; Averbeck, S.; Averbeck, D.;Idaomar, M, Biological effects of essential oils-a review. Food and chemical toxicology. 2008, 46(2) , 446-475.

4. Hammer, K.A .; Carson, C.F , Antimicrobial activity of essential oils and other plant extracts. Journal of applied microbiology. 1999, 86(6), 985-990.

5. Inouye, S.; Takizawa, T.; Yamaguchi, H , Antibacterial activity of essential oils and their major constituents against respiratory tract pathogens by gaseous contact. Journal of antimicrobial chemotherapy. 2001 47(5), 565-573.p

6. Hongbin, S.i .; Jinqiang, H.u .; Zhichang, Liu .; Zhen-ling, Zeng, Antibacterial effect of oregano essential oil alone and in combination with antibiotics against extended-spectrum â-lactamase-producing Escherichia coli. FEMS Immunology \& Medical Microbiology. 2008, 53(2), 190194.p

7. NCCLS (National Committee for Clinical Laboratory Standards): Methods for dilution antimicrobial susceptibility tests of bacteria that grow aerobically. Approved Standard. 2002, M100-S12. 